\title{
Practice Patterns and Use of Endoscopic Retrograde Cholangiopancreatography in the Management of Recurrent Acute Pancreatitis
}

\author{
Jonathan B. Reichstein ${ }^{1}$, Vaishali Patel ${ }^{2}$, Parit Mekaroonkamol ${ }^{2}$, Sunil Dacha², Steven A. Keilin², Qiang Cai $^{2}$ and Field F. Willingham ${ }^{2}$ \\ ${ }^{1}$ Department of Medicine, Duke University, Durham, NC, ${ }^{2}$ Division of Digestive Disease, Department of Medicine, Emory University, Atlanta, \\ GA, USA
}

Background/Aims: There are conflicting opinions regarding the management of recurrent acute pancreatitis (RAP). While some physicians recommend endoscopic retrograde cholangiopancreatography (ERCP) in this setting, others consider it to be contraindicated in patients with RAP. The aim of this study was to assess the practice patterns and clinical features influencing the management of RAP in the US.

Methods: An anonymous 35-question survey instrument was developed and refined through multiple iterations, and its use was approved by our Institutional Review Board. The survey was distributed via email to 408 gastroenterologists to assess the practice patterns in the management of RAP in multiple clinical scenarios.

Results: The survey was completed by 65 participants representing 36 of the top academic/tertiary care centers across the country. Approximately $90.8 \%$ of the participants indicated that they might offer or recommend ERCP in the management of RAP. Multinomial logistic regression analysis revealed that ductal dilatation and presence of symptoms were the most predictive variables $(p<0.001)$ for offering ERCP.

Conclusions: A preponderance of the respondents would consider ERCP among patients with RAP presenting to tertiary care centers in the US. Ductal dilatation, presence of symptoms, and pancreas divisum significantly increased the likelihood of a recommendation for ERCP. Clin Endosc 2020;53:73-81

Key Words: Endoscopic retrograde cholangiopancreatography; Pancreas divisum; Practice patterns; Recurrent acute pancreatitis

\section{INTRODUCTION}

Recurrent acute pancreatitis (RAP) is generally defined as the presence of two or more episodes of AP without concomitant clinical and/or radiographic evidence of chronic pancre-

Received: February 15, 2019 Revised: April 11, 2019

Accepted: April 11, 2019

Correspondence: Field F. Willingham

Division of Digestive Diseases, Department of Medicine, Emory University School of Medicine, 1365 Clifton Road, NE, Building B - Suite 1200, Atlanta, GA 30322, USA

Tel: +1-404-778-3184, Fax: +1-404-778-2925, E-mail: field.willingham@emory. edu

ORCID: https://orcid.org/0000-0002-7071-3001

(c) This is an Open Access article distributed under the terms of the Creative Commons Attribution Non-Commercial License (http://creativecommons.org/ licenses/by-nc/3.0) which permits unrestricted non-commercial use, distribution, and reproduction in any medium, provided the original work is properly cited. atitis. ${ }^{1}$ The estimated incidence of AP is between 15 and 45 per 100,000 persons per year, with a risk of recurrence of nearly $20 \%{ }^{1-6}$ While gallstone diseases and alcohol exposure are generally accepted as the two primary causes of RAP, other etiologies, including autoimmune, hereditary, metabolic, and anatomic variants and Sphincter of Oddi dysfunction (SOD), are also considered. ${ }^{7}$ It has been estimated that up to $30 \%$ of episodes of RAP are idiopathic in nature. ${ }^{8}$

The management of RAP has become a topic of debate, particularly among gastroenterologists, interventional endoscopists, and medical pancreatologists. Some gastroenterologists recommend endoscopic retrograde cholangiopancreatography (ERCP) in this setting, while some do not. ${ }^{9}$ Among patients who undergo ERCP, the specific procedural intervention may vary widely, including biliary sphincterotomy, pancreatic sphincterotomy, pancreatic stent placement, manometry, and 
minor papilla therapy for divisum depending on the clinical context, local practice, and physicians' preference. ${ }^{10-18}$ These more invasive strategies may follow an extensive diagnostic evaluation with laboratory testing, imaging with computed tomography and/or magnetic resonance imaging or cholangiopancreatography with or without secretin enhancement, endoscopic ultrasound (EUS), and Sphincter of Oddi manometry. $^{13}$

In the setting of RAP, it is unclear which patients are being referred for ERCP. In patients who undergo ERCP, it is unclear which interventions are being performed. To consider the proper approach to RAP and to develop the proper trials to determine the appropriate management, it is critical to understand the current practice patterns. Within a subgroup of patients referred for ERCP, it is important to clarify the specific procedural approaches that are being employed. This study examined the national practice patterns for patients presenting with RAP.

\section{MATERIALS AND METHODS}

\section{Overview}

The study protocol was reviewed and was approved by the Institutional Review Board (IRB) at the Emory University School of Medicine.

\section{Survey instrument}

A 35-question survey instrument was developed and refined through multiple iterations to assess the current practice of gastroenterologists in the management of RAP. The final survey was approved by the IRB. The first nine questions assessed demographics, respondent training, type of practice, and experience with ERCP. A total of 20 questions asked the respondents to consider ERCP in the management of RAP considering various factors, including presence of symptoms, pancreatic ductal dilatation, and history of pancreas divisum. Additional questions assessed how alcohol drinking and smoking history may influence the management (Appendix).

\section{Participants}

The survey instrument was distributed via email to 408 gastroenterologists who were identified as leaders in their respective fields in various programs across the US. Emails were sent out two additional times, i.e., at 3 and 6 weeks, to maximize the response rates. An online consent/information sheet, as confirmed by the IRB at the Emory University School of Medicine, accompanied each email that was sent. Consent to participate in the study was determined from voluntary completion of the survey. No additional personal identifiers or any independent information regarding the participants were collected. Responses were collected using a survey tool from Google Forms (Alphabet Inc., Mountain View, CA, USA).

\section{Statistical analysis}

The standard $\chi^{2}$ test and Fisher's exact test were used for comparisons between groups. Multinomial logistic regression testing was conducted to analyze further the effects of multiple variables, including ductal dilatation, pancreas divisum, symptomatology, and sex, on the decision to offer or recommend ERCP. All $p$-tests were two-sided, and a $p$-value of $<0.05$ was considered statistically significant. Statistical analysis was performed using the statistical software JMP Pro 13 (SAS, Cary, NC, USA).

\section{RESULTS}

\section{Respondent demographics}

The survey was completed by 65 participants (15.9\%) representing 36 different academic/tertiary centers across the country, with $87.7 \%$ identified as having been in practice for at least 6 years and $52.3 \%$ performing at least 250 ERCPs each year. Additionally, $73.8 \%$ of the respondents were identified as a pancreatologist or specialized in pancreatology, and $70.8 \%$ had completed a fellowship training in advanced endoscopy. Their demographics are summarized in Table 1.

Table 1. Demographic Features of Survey Respondents

\begin{tabular}{ll}
\hline Demographic category & $\boldsymbol{n}(\%)$ \\
\hline Number of respondents & $65(15.9)$ \\
Number of programs represented & 36 \\
\hline Average years in practice (mean \pm SD) & $13.5 \pm 7.13$ \\
\hline Completed fellowship in advanced endoscopy, $n(\%)$ & $46(70.8)$ \\
\hline Considers self to be specialized in pancreatology, $n(\%)$ & $48(73.8)$ \\
\hline Performs ERCP, $n(\%)$ & $54(83.1)$ \\
\hline Performs $251+$ ERCPs per year, $n(\%)$ & $34(52.3)$ \\
Performs biliary sphincterotomy, $n(\%)$ & $53(81.5)$ \\
\hline Performs pancreatic sphincterotomy, $n(\%)$ & $50(76.9)$ \\
Performs pancreatic duct cannulation, $n(\%)$ & $51(78.5)$ \\
Performs minor papillotomy, $n(\%)$ & $50(76.9)$ \\
\hline Performs EUS, $n$ (\%) & $49(75.4)$ \\
\hline Performs SOM, $n$ (\%) & $17(26.2)$ \\
\hline
\end{tabular}

ERCP, endoscopic retrograde cholangiopancreatography; EUS, endoscopic ultrasound; SD, standard deviation; SOM, sphincter of Oddi manometry. 


\section{Practice patterns}

The respondents were asked to indicate their estimate of the most common etiologies for RAP. In response, 38.5\% of the participants reported that alcohol abuse was the primary etiology of RAP in their cohort, while $35.4 \%$ reported an idiopathic etiology. Similarly, 38.5\% of the respondents noted that greater than or equal to two episodes of RAP were needed before intervening with ERCP, with another 20\% believing that greater than or equal to three episodes of RAP were required; further, $33.8 \%$ claimed that the number of episodes of RAP did not influence their decision to offer or recommend ERCP.

Approximately $90.8 \%$ of the participants reported that they might offer or recommend ERCP in the management of RAP. For patients with pancreatic ductal dilatation and pancreas divisum, 95.4\% ( $p<0.001)$ might offer ERCP (Table 2).

Multinomial logistic regression testing was performed to characterize further the impact of ductal dilatation, pancreas divisum, pancreatic-type symptomatology (e.g., epigastric pain), and sex on the decision to offer or recommend ERCP (Table 3, Fig. 1). The respondents were most likely to recommend ERCP in symptomatic female patients with pancreas divisum and pancreatic ductal dilatation (96.9\%, $p<0.001$ ), with $92.3 \%(p<0.001)$ indicating that they would offer ERCP to male patients in the same scenario. For asymptomatic female patients with pancreas divisum and pancreatic ductal dilatation, $72.3 \%$ ( $p=0.005)$ of the respondents would offer ERCP; conversely, $78.5 \%(p<0.001)$ would offer ERCP to male

Percentage of participants who would consider ERCP for patients with without pancreas divisum by clinical scenario

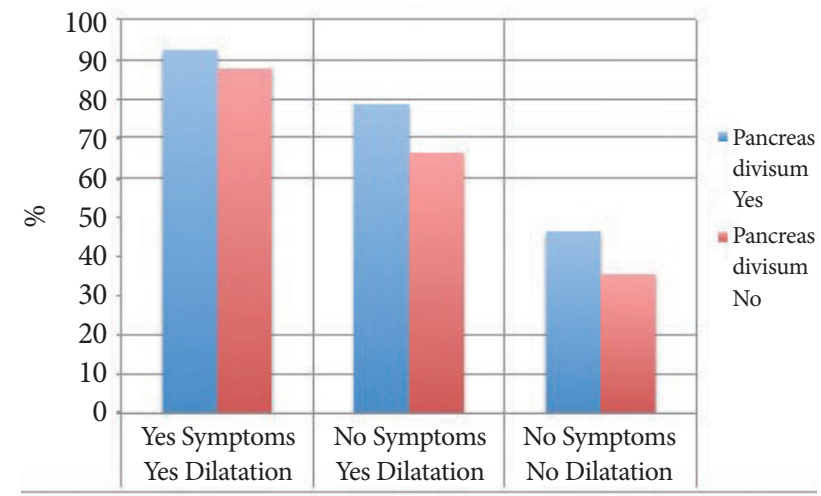

Fig. 1. Proportion of respondents who would offer endoscopic retrograde cholangiopancreatography (ERCP) considering different factors. The more factors a patient had-including the presence of pancreatic ductal dilatation (e.g., $6 \mathrm{~mm}$ ), a history of pancreas divisum, and the presence of pancreatic-type pain-the higher the response rate for ERCP.

Table 2. Univariate Analysis of Dilatation and Pancreas Divisum on Endoscopic Retrograde Cholangiopancreatography

\begin{tabular}{lccc}
\hline Variable & $\begin{array}{c}\text { Would perform ERCP } \\
\boldsymbol{n}(\boldsymbol{\%})\end{array}$ & $\begin{array}{c}\text { Would not perform ERCP } \\
\boldsymbol{n}(\boldsymbol{\%})\end{array}$ & $\boldsymbol{p}$-value \\
\hline Duct dilatation & $62(95.4)$ & $3(4.6)$ & $<0.001$ \\
Pancreas divisum & $62(95.4)$ & $3(4.6)$ & $<0.001$ \\
\hline
\end{tabular}

ERCP, endoscopic retrograde cholangiopancreatography.

Table 3. Multinomial Logistic Regression on the Recommendation to Offer Endoscopic Retrograde Cholangiopancreatography

\begin{tabular}{lccccc}
\hline Gender & Pancreas divisum & PD dilatation & $\begin{array}{c}\text { Pancreatic-type symp- } \\
\text { toms }\end{array}$ & $\begin{array}{c}\text { Would offer ERCP } \\
\boldsymbol{n}(\%)\end{array}$ & $\boldsymbol{p}$-value \\
\hline Male & Yes & Yes & Yes & $60(92.3)$ & $<7(87.7)$ \\
Male & No & Yes & Yes & $51(78.5)$ & $<0.001$ \\
Male & Yes & Yes & No & $43(66.2)$ & 0.001 \\
Male & No & Yes & No & $30(46.2)$ & 0.011 \\
Male & Yes & No & No & $23(35.4)$ & 0.53 \\
Male & No & No & No & $63(96.9)$ & 6.021 \\
Female & Yes & Yes & Yes & 601 & $<0.001$ \\
Female & No & Yes & Yes & $47(72.3)$ & $<0.001$ \\
Female & Yes & Yes & No & $45(69.2)$ & 0.005 \\
Female & No & Yes & No & $33(50.8)$ & 0.003 \\
Female & Yes & No & No & $27(41.5)$ & 0.901 \\
Female & No & No & No & 0.17 \\
\hline
\end{tabular}

ERCP, endoscopic retrograde cholangiopancreatography; PD, pancreatic duct. 
patients in the same scenario. Taken together, pancreatic ductal dilatation and presence of pancreatic-related symptoms were the most predictive variables for a recommendation for ERCP ( $p<0.001$; Fig. 2). Pancreas divisum was significantly associated with the decision to offer or recommend ERCP ( $p=0.012)$, while sex was not $(p=0.34)$.

There was heterogeneity in the specific interventions during ERCP. At the initial intervention of patients without pancreatic ductal dilatation, $45.9 \%$ would offer biliary sphincterotomy; $11.5 \%$, pancreatic sphincterotomy; and $32.8 \%$, both. In patients with pancreatic ductal dilatation, $66.2 \%$ might perform pancreatic sphincterotomy; $52.3 \%$, biliary sphincterotomy; and $32.8 \%$, both; further, $95.4 \%$ noted that they would also offer EUS in this scenario (Table 4).

\section{DISCUSSION}

The proper management of RAP remains controversial. Some providers recommend ERCP, while some suggest that ERCP should be avoided in patients with pancreatitis. Within groups of patients referred for ERCP, there is also considerable heterogeneity in the specific approaches taken. This study investigated the practice patterns and the use of ERCP

\section{Multionmial regression analysis of different variables influencing the} decision to offer ERCP

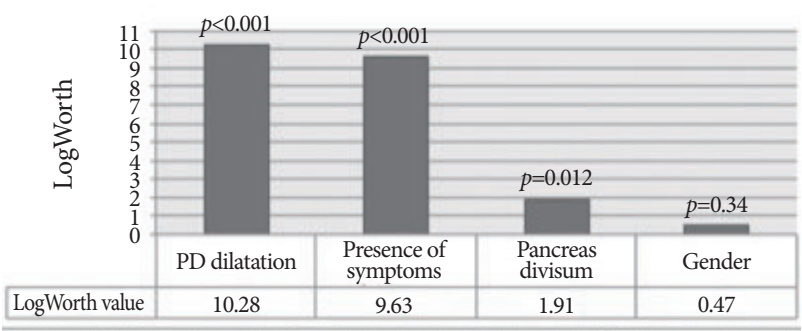

Fig. 2. Graphical representation of the multinomial logistic regression testing assessing the impact of several clinical features on the recommendation to offer endoscopic retrograde cholangiopancreatography (ERCP) in patients with recurrent acute pancreatitis. Pancreatic ductal dilatation appeared to be the single most impactful factor, followed by symptomatology. PD, pancreatic duct. in the management of RAP in a large sample of practitioners treating patients with pancreatic diseases in the US. We found that a high proportion of gastroenterologists (90.8\%) would consider ERCP for patients presenting with RAP. Several factors increased the likelihood of a recommendation for endoscopic intervention, including ductal dilatation, divisum, and presence of symptoms. Some factors, such as sex, were not significant. In patients undergoing ERCP, a small proportion (45.9\%) would perform biliary sphincterotomy as the first intervention; however, the specific approaches taken at the index ERCP varied. In the US, gastroenterologists are likely to consider ERCP as a therapeutic modality for patients presenting with RAP.

A number of factors may influence a practitioner's decision to recommend ERCP, including the presence of pancreatic ductal dilatation (e.g., $6 \mathrm{~mm}$ ), history of pancreas divisum, and presence of pancreatic-type pain. The more factors that a patient had, the higher the response rate for ERCP (Fig. 1). For example, $95.4 \%$ of the respondents would consider recommending ERCP when a patient had either pancreatic ductal dilatation or a history of pancreas divisum. While $96.9 \%$ of the respondents would offer or recommend ERCP to a patient with pancreatic ductal dilatation, a history of pancreas divisum, and abdominal symptoms, only $35.4 \%$ would consider ERCP in a patient with a normal duct, no history of pancreas divisum, and no symptoms. Among all the factors studied, pancreatic ductal dilatation appeared to be the single most impactful factor, followed by symptomatology. While pancreas divisum was significantly associated with a recommendation for ERCP, it was a weaker predictor (Table 3, Fig. 2).

Sex was not a significant factor in the decision to offer ERCP. Generally, the respondents were somewhat more likely to recommend ERCP in female patients relative to male patients with a similar presentation. For example, $96.9 \%$ of the respondents would offer ERCP to a female patient with ductal dilatation, symptomatology, and a history of pancreas divisum compared with $92.3 \%$ recommending such to a male patient in the same scenario. Some studies have identified female sex to be a significant risk factor for post-ERCP pancreatitis, while others have not. ${ }^{19-27}$ However, there are no available data

Table 4. Specific Interventions in the Management of Recurrent Acute Pancreatitis with a Dilatated Pancreatic Duct Compared to Non-Dilatated Pancreatic Duct

\begin{tabular}{|c|c|c|c|}
\hline Intervention & $\begin{array}{c}\text { Dilatated PD } \\
n(\%)\end{array}$ & $\begin{array}{c}\text { Non-dilatated PD } \\
n(\%)\end{array}$ & $p$-value \\
\hline Pancreatic duct cannulation & $50(76.9)$ & $50(76.9)$ & 1 \\
\hline Pancreatic sphincterotomy & $43(66.2)$ & $7(11.5)$ & $<0.001$ \\
\hline Biliary sphincterotomy & $34(52.3)$ & $28(45.9)$ & 0.38 \\
\hline Both pancreatic and biliary sphincterotomy & $26(32.8)$ & $26(32.8)$ & 1 \\
\hline
\end{tabular}

$\mathrm{PD}$, pancreatic duct. 
on the differential outcomes following ERCP according to sex.

The respondents also indicated the specific approaches they would take during ERCP (Table 4). At the initial intervention of patients without pancreatic ductal dilatation, $45.9 \%$ of the respondents would offer biliary sphincterotomy. A retrospective study found that biliary sphincterotomy alone may be as effective as other interventions. ${ }^{16}$ Among patients with pancreatic ductal dilatation, $66.2 \%$ might perform pancreatic sphincterotomy; $52.3 \%$, biliary sphincterotomy; and $32.8 \%$, both; moreover, $95.4 \%$ noted that they would also offer EUS in this scenario (Table 4). Previous studies have suggested that a dilated duct may be associated with greater clinical success in ductal cannulation compared with a normal-sized duct, ${ }^{28,29}$ and ductal dilatation is often considered to indicate an obstructive process, which might be mitigated by ERCP.

Among patients with both RAP and a history of pancreas divisum, some approaches-including minor papilla stenting - have yielded success rates of $91.7 \%$ in limiting or improving symptoms, including reduced rates of pancreatic-type pain, hospitalization, or pancreatitis. ${ }^{11,12,30}$ Other studies addressing ERCP in patients with idiopathic RAP or SOD reported an efficacy rate of $42 \%-89 \%$ when analyzing the role of biliary stenting, pancreatic stenting, or both. ${ }^{16,31-35}$ In patients with SOD, studies have reported similar efficacy with biliary stenting and dual stenting. ${ }^{16}$ While many respondents would recommend ERCP in some settings for patients with RAP, there is considerable heterogeneity in the specific approach, which would be taken at the index ERCP. An ongoing prospective clinical trial may provide relevant information on the outcomes of interventions for patients with divisum; ${ }^{36}$ similar work may be indicated for RAP with conventional ductal anatomy.

There were a number of limitations in this study. Selection and recall biases are possible given the subjective nature of the survey approach. While this anonymous IRB-approved survey instrument was sent to a large number of gastroenterologists across the country, the majority who responded (70.8\%) had completed a fellowship training in advanced endoscopy. Nearly three-quarters were identified as a pancreatologist or specialized in pancreatology, and over half performed over 250 ERCPs each year in their practice. Thus, there may be limitations in the generalizability of the findings to the larger community outside of the tertiary care setting. Inherent in a practice survey design, there may be differences in the perception of practice approaches and actual providers' practice. There has been no available validated survey instrument that could capture specific data on the decision to offer ERCP in RAP and that could evaluate the specific procedural interventions performed in patients undergoing such. Therefore, as with other surveys in endoscopic practice, ${ }^{17}$ an original survey instrument was developed.

In conclusion, this study found that ERCP is often recommended in tertiary care institutions for patients presenting with RAP. Some factors, such as ductal dilatation and presence of symptoms, significantly increased the likelihood of ERCP recommendation. There was considerable heterogeneity among the specific interventions performed at the index ERCP. These data highlight the need to determine the subset of patients for whom ERCP may be beneficial and what approaches are the most effective. While the consensus definitions are clear, our understanding of the management for patients with RAP is evolving.

\section{Conflicts of Interest}

The authors have no financial conflicts of interest.

\section{Acknowledgements}

The authors would like to thank the following physicians and staff for their invaluable input and assistance in this project. Venkata Akshintala, Harry Aslanian, Augustin Attwell, Todd Baron, Alin Botoman, James Buxbaum, Lisa Cassani, Amitahb Chak, Jennifer Christie, Victor Ciofoaia, Gregory Cote, Peter Cotton, Sarah Cristofaro, Christopher DiMaio, David Desliets, Peter Draganov, Steven A. Edmundowicz, Grace Elta, Jeffrey Easler, Joseph Elmunzer, Evan Fogel, David Forcione, Christopher Forsmark, A. Jay Freeman, Martin Freeman, Anthony Gamboa, Timothy Gardner, Gregory Ginsberg, Wendy Ho, Brian Jacobson, Kunal Jajoo, Michel Kahaleh, Peter Kelsey, Jason Klapman, Michael Kochman, Christopher Lind, Robert Lockwood, Raimondo Massimo, Klaus Mönkemüller, Daniel Mullady, Jose Nieto, Keith Obstein, Mohamed Othman, Georgios Papachristou, Octavia Pickett-Blakely, Teodor Pitea, Douglas Pleskow, John Poneros, Gottumukkala S. Raju, John Saltzman, James Scheiman, Amrita Sethi, Janak Shah, Raj Shah, Ali Siddiqui, Vikesh Singh, Mahir Waghi, Michael Wallace, Andrew Wang, Sachin Wani, Rabindra Watson, C. Mel Wilcox and Patrick Yachimski.

\section{REFERENCES}

1. Das R, Yadav D, Papachristou GI. Endoscopic treatment of recurrent acute pancreatitis and smoldering acute pancreatitis. Gastrointest Endosc Clin N Am 2015;25:737-748.

2. Machicado JD, Yadav D. Epidemiology of recurrent acute and chronic pancreatitis: similarities and differences. Dig Dis Sci 2017;62:1683-1691.

3. Yadav D, Lowenfels AB. Trends in the epidemiology of the first attack of acute pancreatitis: a systematic review. Pancreas 2006;33:323-330.

4. Shen HN, Lu CL, Li CY. Epidemiology of first-attack acute pancreatitis in Taiwan from 2000 through 2009: a nationwide population-based study. Pancreas 2012;41:696-702.

5. Omdal T, Dale J, Lie SA, Iversen KB, Flaatten H, Ovrebo K. Time trends in incidence, etiology, and case fatality rate of the first attack of acute pancreatitis. Scand J Gastroenterol 2011;46:1389-1398.

6. Sankaran SJ, Xiao AY, Wu LM, Windsor JA, Forsmark CE, Petrov MS. Frequency of progression from acute to chronic pancreatitis and risk factors: a meta-analysis. Gastroenterology 2015;149:1490-1500.e1.

7. Roberts JR, Romagnuolo J. Endoscopic therapy for acute recurrent pancreatitis. Gastrointest Endosc Clin N Am 2013;23:803-819.

8. Steinberg W, Tenner S. Acute pancreatitis. N Engl J Med 1994;330:11981210.

9. Gabbrielli A, Pezzilli R, Uomo G, et al. ERCP in acute pancreatitis: what takes place in routine clinical practice? World J Gastrointest Endosc 
2010;2:308-313.

10. Somani P, Navaneethan U. Role of ERCP in patients with idiopathic recurrent acute pancreatitis. Curr Treat Options Gastroenterol 2016;14:327-339.

11. Kaw M, Brodmerkel GJ Jr. ERCP, biliary crystal analysis, and sphincter of Oddi manometry in idiopathic recurrent pancreatitis. Gastrointest Endosc 2002;55:157-162.

12. Mariani A, Di Leo M, Petrone MC, et al. Outcome of endotherapy for pancreas divisum in patients with acute recurrent pancreatitis. World J Gastroenterol 2014;20:17468-17475.

13. Bin-Sagheer ST, Brady PG, Mamel JJ, Robinson B. Reduction in the incidence of pancreatitis in patients undergoing sphincter of Oddi manometry: a successful quality improvement project. South Med J 2003;96:223-225.

14. Brackbill S, Young S, Schoenfeld P, Elta G. A survey of physician practices on prophylactic pancreatic stents. Gastrointest Endosc 2006;64:4552.

15. Saltzman JR. Endoscopic treatment of pancreas divisum: why, when, and how? Gastrointest Endosc 2006;64:712-715

16. Coté GA, Imperiale TF, Schmidt SE, et al. Similar efficacies of biliary, with or without pancreatic, sphincterotomy in treatment of idiopathic recurrent acute pancreatitis. Gastroenterology 2012;143:1502-1509.e1.

17. Watson RR, Klapman J, Komanduri S, Shah JN, Wani S, Muthusamy R. Wide disparities in attitudes and practices regarding Type II sphincter of Oddi dysfunction: a survey of expert U.S. endoscopists. Endosc Int Open 2016;4:E941-E946.

18. Fogel EL, Toth TG, Lehman GA, DiMagno MJ, DiMagno EP. Does endoscopic therapy favorably affect the outcome of patients who have recurrent acute pancreatitis and pancreas divisum? Pancreas 2007;34:2145.

19. Moffatt DC, Coté GA, Avula H, et al. Risk factors for ERCP-related complications in patients with pancreas divisum: a retrospective study. Gastrointest Endosc 2011;73:963-970.

20. Chen JJ, Wang XM, Liu XQ, et al. Risk factors for post-ERCP pancreatitis: a systematic review of clinical trials with a large sample size in the past 10 years. Eur J Med Res 2014;19:26.

21. Cotton PB, Garrow DA, Gallagher J, Romagnuolo J. Risk factors for complications after ERCP: a multivariate analysis of 11,497 procedures over 12 years. Gastrointest Endosc 2009;70:80-88.

22. Perney P, Berthier E, Pageaux GP, et al. Are drugs a risk factor of post-ERCP pancreatitis? Gastrointest Endosc 2003;58:696-700.

23. Testoni PA, Mariani A, Giussani A, et al. Risk factors for post-ERCP pancreatitis in high- and low-volume centers and among expert and non-expert operators: a prospective multicenter study. Am J Gastroen- terol 2010;105:1753-1761.

24. Wilcox CM, Phadnis M, Varadarajulu S. Biliary stent placement is associated with post-ERCP pancreatitis. Gastrointest Endosc 2010;72:546550 .

25. Cheng CL, Sherman S, Watkins JL, et al. Risk factors for post-ERCP pancreatitis: a prospective multicenter study. Am J Gastroenterol 2006;101:139-147.

26. Zhou W, Li Y, Zhang Q, et al. Risk factors for postendoscopic retrograde cholangiopancreatography pancreatitis: a retrospective analysis of 7,168 cases. Pancreatology 2011;11:399-405.

27. Christensen M, Matzen P, Schulze S, Rosenberg J. Complications of ERCP: a prospective study. Gastrointest Endosc 2004;60:721-731.

28. Barkay O, Sherman S, McHenry L, et al. Therapeutic EUS-assisted endoscopic retrograde pancreatography after failed pancreatic duct cannulation at ERCP. Gastrointest Endosc 2010;71:1166-1173.

29. Mallery S, Matlock J, Freeman ML. EUS-guided rendezvous drainage of obstructed biliary and pancreatic ducts: report of 6 cases. Gastrointest Endosc 2004;59:100-107.

30. Romagnuolo J, Durkalski V, Fogel EL, et al. Outcomes after minor papilla endoscopic sphincterotomy (MPES) for unexplained acute pancreatitis and pancreas divisum: final results of the multicenter prospective FRAMES (frequency of recurrent acute pancreatitis after minor papilla endoscopic sphincterotomy) study. Gastrointest Endosc 2013;77(5 Sup$\mathrm{pl}): \mathrm{AB} 379$.

31. Testoni PA, Caporuscio S, Bagnolo F, Lella F. Idiopathic recurrent pancreatitis: long-term results after ERCP, endoscopic sphincterotomy, or ursodeoxycholic acid treatment. Am J Gastroenterol 2000;95:1702-1707.

32. Wehrmann T. Long-term results ( $\geq 10$ years) of endoscopic therapy for sphincter of Oddi dysfunction in patients with acute recurrent pancreatitis. Endoscopy 2011;43:202-207.

33. Das R, Clarke B, Tang G, et al. Endoscopic sphincterotomy (ES) may not alter the natural history of idiopathic recurrent acute pancreatitis (IRAP). Pancreatology 2016;16:770-777.

34. Jacob L, Geenen JE, Catalano MF, Geenen DJ. Prevention of pancreatitis in patients with idiopathic recurrent pancreatitis: a prospective nonblinded randomized study using endoscopic stents. Endoscopy 2001;33:559-562.

35. Guo A, Poneros JM. The role of endotherapy in recurrent acute pancreatitis. Gastrointest Endosc Clin N Am 2018;28:455-476.

36. Cote GA. SpHincterotomy for acute recurrent pancreatitis (SHARP) [Internet]. Bethesda (MD): ClinicalTrials.gov; c2018 [updated 2019 May 23; cited 2019 May 23]. Available from: https://clinicaltrials.gov/ct2/ show/NCT03609944. 


\section{APPENDIX}

\section{Questionnaire}

1. In what setting is your gastroenterology practice?*

$\square$ Tertiary/academic center

$\square$ Private practice

Other:

2. Did you complete advanced endoscopy training?*

$\square$ Yes

$\square$ No

3. How many years have you been in practice?*

$\square 0-5$

$\square$ 6-10

$\square$ 11-15

$\square$ 15-20

$\square 20+$

4. Do you consider yourself to be a pancreatologist or specialized in pancreatology?*

$\square$ Yes

$\square$ No

5. In your current practice, which of the following procedures do you perform? Select all that apply.*

$\square$ ERCP

$\square$ Endoscopic ultrasound (EUS)

$\square$ Sphincter of Oddi manometry

$\square$ Pancreatic sphincterotomy

$\square$ Biliary sphincterotomy

$\square$ Pancreatic ductal cannulation

$\square$ Minor papillotomy

$\square$ I do not perform any of these procedures.

6. Approximately how many ERCPs do you perform each year?*

$\square$ None

$\square 1-100$

$\square$ 101-250

$\square 251+$

7. On average, how many patients with recurrent acute pancreatitis (RAP) do you manage each month?*

$\square 0-5$

$\square$ 6-10

$\square$ 11-15

$\square 15+$
8. Of the patients with RAP that you manage, what is the most common etiology of their disease?*

$\square$ Alcohol abuse

$\square$ Gallstone disease

$\square$ Pancreas divisum

$\square$ Sphincter of Oddi dysfunction

$\square$ Anomalous pancreaticobiliary junction

$\square$ Idiopathic

$\square$ Hereditary

Autoimmune

Other:

9. Among the patients that you manage with RAP, on average, how many episodes of RAP have they had?*

$\square 2$

$\square 3$

$\square 4$

$\square 5+$

10. In some settings, might you offer or recommend ERCP for RAP?*

$\square$ Yes

$\square$ No

11. After how many episodes of RAP do you believe that management with ERCP may be warranted?*

$\square$ Greater than or equal to two

$\square$ Greater than or equal to three

$\square$ Greater than or equal to four

$\square$ Greater than or equal to five

$\square$ I do not believe that ERCP is warranted in the management of RAP.

$\square$ The number of RAP episodes does not influence my decision to offer ERCP.

12. In a patient with RAP found to have PANCREATIC DUCTAL DILATATION, might you offer or recommend ERCP?*

$\square$ Yes

$\square$ No

13. In a patient with RAP found to have NO PANCREATIC DUCTAL DILATATION, might you offer or recommend ERCP?*

$\square$ Yes

$\square$ No

14. In a patient with RAP found to have PANCREATIC DUC- 
TAL DILATATION, which of the following procedures might you offer or recommend? Check all that apply.*

$\square$ EUS

$\square$ Pancreatic ductal cannulation

Pancreatic sphincterotomy

Biliary sphincterotomy

$\square$ Minor papillotomy

$\square$ None of the options listed; if you select this option, please describe below what other interventions you would offer or recommend.

Other:

15. If you offer ERCP for RAP, what would be your approach at the initial procedure?

$\square$ Biliary sphincterotomy

Pancreatic sphincterotomy

$\square$ Both biliary and pancreatic sphincterotomies

$\square$ I do not recommend ERCP in this setting.

16. In a patient with RAP, a history of pancreas divisum, and PANCREATIC DUCTAL DILATATION, might you offer or recommend ERCP?*

$\square$ Yes

$\square$ No

17. In a patient with RAP and a history of pancreas divisum but WITHOUT PANCREATIC DUCTAL DILATATION, might you offer or recommend ERCP?*

$\square$ Yes

$\square$ No

18. For a patient with RAP and pancreas divisum, might you recommend genetic testing prior to ERCP?

$\square$ Yes

$\square$ No

19. Might you order genetic testing for hereditary pancreatitis for patients presenting with RAP?

$\square$ Yes, for most patients

$\square$ Yes, but only patients with a family history

Yes, but only for patients aged $<25$ years

$\square$ No

20. Do you believe that alcohol abuse may contribute to RAP development?*

$\square$ Yes

$\square$ No

21. In a patient with RAP who drinks 7-14 alcoholic beverages per week, might you require alcohol cessation prior to intervention with ERCP?*

$\square$ Yes

$\square$ No

22. Do you believe that heavy tobacco exposure may contribute to RAP development?*

$\square$ Yes

$\square$ No

23. For an elderly patient with RAP and no evidence of a mass on cross-sectional imaging, might you recommend or offer EUS to exclude a malignancy prior to offering ERCP?

$\square$ Yes

$\square$ No

24. A 64-year-old SYMPTOMATIC MALE PATIENT with greater than two episodes of RAP presents to your office complaining of intermittent epigastric pain, found to have PANCREATIC DUCTAL DILATATION $(6 \mathrm{~mm})$; the rest of the workup findings are found to be negative. Might you offer or recommend ERCP in this setting?*

$\square$ Yes

$\square$ No

25. A 64-year-old ASYMPTOMATIC MALE PATIENT with greater than two episodes of RAP presents to your office, found to have PANCREATIC DUCTAL DILATATION (6 $\mathrm{mm}$ ); the rest of the workup findings are found to be negative. Might you offer or recommend ERCP in this setting?* $\square$ Yes

$\square$ No

26. A 64-year-old ASYMPTOMATIC MALE PATIENT with greater than two episodes of RAP presents to your office, found to have NO PANCREATIC DUCTAL DILATATION $(3 \mathrm{~mm})$; the rest of the workup findings are found to be negative. Might you offer or recommend ERCP in this setting?*

$\square$ Yes

$\square$ No

27. A 64-year-old SYMPTOMATIC MALE PATIENT with greater than two episodes of RAP and a history of PANCREAS DIVISUM presents to your office complaining of intermittent epigastric pain, found to have PANCREATIC DUCTAL DILATATION (6 mm); the rest of the workup findings are found to be negative. Might you offer or recommend ERCP in this setting?*

$\square$ Yes

$\square$ No 
28. A 64-year-old ASYMPTOMATIC MALE PATIENT with greater than two episodes of RAP and a history of PANCREAS DIVISUM presents to your office, found to have PANCREATIC DUCTAL DILATATION (6 mm); the rest of the workup findings are found to be negative. Might you offer or recommend ERCP in this setting?*

$\square$ Yes

$\square$ No

29. A 64-year-old ASYMPTOMATIC MALE PATIENT with greater than two episodes of RAP and a history of PANCREAS DIVISUM presents to your office, found to have NO PANCREATIC DUCTAL DILATATION (3 mm); the rest of the workup findings are found to be negative. Might you offer or recommend ERCP in this setting?*

$\square$ Yes

$\square$ No

30. A 34-year-old SYMPTOMATIC FEMALE PATIENT with greater than two episodes of RAP presents to your office complaining of intermittent epigastric pain, found to have PANCREATIC DUCTAL DILATATION (6 mm); the rest of the workup findings are found to be negative. Might you offer or recommend ERCP in this setting?*

$\square$ Yes

$\square$ No

\section{A 34-year-old ASYMPTOMATIC FEMALE PATIENT} with greater than two episodes of RAP presents to your office, found to have PANCREATIC DUCTAL DILATATION (6 mm); the rest of the workup findings are found to be negative. Might you offer or recommend ERCP in this setting?*

$\square$ Yes

$\square$ No
32. A 34-year-old ASYMPTOMATIC FEMALE PATIENT with greater than two episodes of RAP presents to your office, found to have NO PANCREATIC DUCTAL DILATATION ( $3 \mathrm{~mm})$; the rest of the workup findings are found to be negative. Might you offer or recommend ERCP in this setting?*

$\square$ Yes

$\square$ No

33. A 34-year-old SYMPTOMATIC FEMALE PATIENT with greater than two episodes of RAP and a history of PANCREAS DIVISUM presents to your office complaining of intermittent epigastric pain, found to have PANCREATIC DUCTAL DILATATION (6 mm); the rest of the workup findings are found to be negative. Might you offer or recommend ERCP in this setting?*

$\square$ Yes

$\square$ No

34. A 34-year-old ASYMPTOMATIC FEMALE PATIENT with greater than two episodes of RAP and a history of PANCREAS DIVISUM presents to your office, found to have PANCREATIC DUCTAL DILATATION (6 mm); the rest of the workup findings are found to be negative. Might you offer or recommend ERCP in this setting?*

$\square$ Yes

$\square$ No

35. A 34-year-old ASYMPTOMATIC FEMALE PATIENT with greater than two episodes of RAP and a history of PANCREAS DIVISUM presents to your office, found to have NO PANCREATIC DUCTAL DILATATION (3 $\mathrm{mm}$ ); the rest of the workup findings are found to be negative. Might you offer or recommend ERCP in this setting?* $\square$ Yes

$\square$ No 